\title{
RESISTÊNCIA MECÂNICA DO SOLO À PENETRAÇÃO NA BACIA HIDROGRÁFICA DO RIACHO FUNDO, FELIXLÂNDIA-MG ${ }^{1}$
}

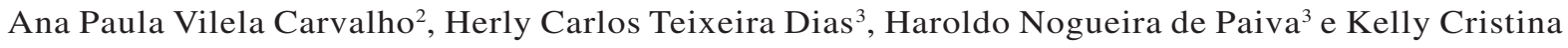 \\ Tonello ${ }^{4}$
}

\begin{abstract}
RESUMO - A compactação do solo devido ao tráfego de máquinas utilizadas no setor florestal causa modificações estruturais deste, podendo assim interferir na densidade do solo, velocidade e capacidade de infiltração de água e no desenvolvimento radicular das culturas. Objetivou-se, neste trabalho avaliar a resistência mecânica do solo à penetração na Bacia Hidrográfica do Riacho Fundo, Felixlândia-MG em área de uma empresa do setor florestal localizada no cerrado mineiro. Os testes de resistência à penetração foram realizados em fevereiro de 2011, em seis parcelas com plantios de eucalipto localizadas nos talhões 35, 36, 39, 40, 42 e 44, utilizando-se um penetrômetro de impacto. Os talhões apresentaram valores médios da resistência mecânica do solo acima de $4 \mathrm{MPa}$ e esses altos valores podem estar associados ao uso do solo que antes dos plantios de eucalipto era pastagem e também devido a condição de baixo teor de umidade do solo no período em que foi realizada a determinação da resistência mecânica do solo.
\end{abstract}

Palavras-chave: Eucalipto, Compactação do solo e Penetrômetro de impacto.

\section{RESISTANCE MECHANICS OF SOIL TO PENETRATION IN THE RIACHO FUNDO WATERSHADE, FELIXLÂNDIA-MG}

\begin{abstract}
Soil compaction due to traffic of machines used in forestry sector causes structural changes on it, it can interfere with the bulk density, speed and water infiltration and root development of crops. The objective of this study was to evaluate the mechanical resistance to penetration in the Riacho Fundo watershade, Felixlândia-MG in an area belonging to a forest sector company located in the Cerrado miner. The penetration resistance tests were conducted in February 2011 in six plots with eucalyptus plantations located on plots 35, 36, 39, 40, 42 and 44, using an impact penetrometer. The plots showed average values of soil mechanical resistance above $4 \mathrm{MPa}$ and these high values may be associated with the use of the soil before planting eucalyptus as pasture and also due to the condition of low soil moisture in the period to determine the mechanical resistance of the soil.
\end{abstract}

Keywords: Eucalyptus, Soil Compaction and Penetrometer impact.

\section{INTRODUÇÃO}

A ausência de planejamento no manejo florestal de uma bacia hidrográfica faz que o uso de técnicas inadequadas acabe gerando um ciclo de consequências negativas. Entre elas estão a má conservação do solo e da água, a erosão, a baixa produtividade e as perdas econômicas e ambientais.

As modificações estruturais causadas no solo pelos diferentes sistemas de manejo podem resultar em maior ou menor compactação, o que poderá interferir na

\footnotetext{
${ }^{1}$ Recebido em 21.03.2012 aceito para publicação em 04.06.2012

${ }^{2}$ Pós-Graduação em Meteorologia Agrícola, Universidade Federal de Viçosa, UFV, Brasil. E-mail: <ana.vilela@ufv.br>.

${ }^{3}$ Universidade Federal de Viçosa-UFV, Departamento de Engenharia Florestal. E-mail: <herly@ufv.br>e < hnpaiva@ufv.br $>$.

${ }^{4}$ Universidade Federal de São Carlos- Departamento de Ciências Ambientais, Campus Sorocaba-SP. E-mail: < kellytonello@ yahoo.com>.
} 
densidade do solo, na porosidade, na infiltração de água no solo e no desenvolvimento radicular das culturas (POGGIANI, 1996; TAVARES FILHO et al., 2001).

A compactação do solo devido ao tráfego de máquinas de colheita e transporte florestal que trafegam com frequência numa mesma linha, assim como a extensão da área impactada, constitui fator de preocupação, em razão da possibilidade de efeitos prejudiciais para o crescimento da floresta (SEIXAS; SOUZA, 2007; SILVA et al., 2007).

A compactação do solo é um processo resultante de tensões recebidas em uma área, através da mecanização ou pelo pisoteio de animais. A distribuição da compactação no perfil do solo é variável de acordo com a intensidade das pressões externas aplicadas ao solo, tipo de solo e teor de umidade (RAPER; ERBACH, 1990).

Segundo Costa et al. (2003), a densidade do solo tende a aumentar com a profundidade, o que se deve a fatores como: teor reduzido de matéria orgânica, menor agregação, menor penetração de raízes, maior compactação ocasionada pelo peso das camadas sobrejacentes, diminuição da porosidade total devido à eluviação de argila, entre outros.

O uso do penetrômetro de impacto, aparelho que mede a resistência mecânica do solo à penetração, permite identificar a profundidade em que se encontram as camadas, naturalmente adensadas ou compactadas devido ao manejo inadequado do solo. O penetrômetro de impacto tem como princípio de funcionamento a penetração de uma haste com ponteira com área de projeção no solo através do impacto de um êmbolo de massa conhecida a uma altura constante. No Brasil, penetrômetros de impacto têm sido bastante utilizados em estudos de ciência do solo para avaliar o efeito de manejo sobre a compactação do solo (STOLF et al., 1998).

De acordo com Benghough e Mullins (1990), os penetrômetros fornecem boas estimativas da resistência mecânica do solo à penetração, uma vez que apresentam como principais vantagens a facilidade e rapidez na obtenção dos resultados. Mas o uso do penetrômetro também apresenta desvantagens devido à influência da presença de raízes e rochas no solo que aumentam os valores da resistência mecânica e também os efeitos do teor de água do solo nas leituras, cuja diminuição geralmente implica aumento da resistência ao penetrômetro (SEIXAS; SOUZA, 2007).

Diante do exposto, este trabalho teve por objetivo avaliar a resistência mecânica do solo à penetração em talhões de eucalipto na Bacia Hidrográfica do Riacho Fundo, em Felixlândia, MG.

\section{MATERIAL E MÉTODOS}

\subsection{Localização e caracterização da área de estudo}

A Bacia Hidrográfica do Riacho Fundo deságua na represa de Três Marias, rio São Francisco. O estudo foi realizado na bacia de cabeceira, que é tipicamente florestal e está localizada no Município de Felixlândia, MG. A bacia de cabeceira possui uma área de 719,92 ha e é ocupada, em sua maior parte, com talhões de eucalipto $(81,7 \%)$, possui $8,5 \%$ das terras com estradas florestais e $9,8 \%$ de reserva (Cerrado).

O Município de Felixlândia está localizado na região Centro Norte de Minas Gerais. Apresenta altitudes máximas e mínimas de 961 m e 502 m, respectivamente. Conforme a classificação de Köppen, o clima da região caracteriza-se por ser úmido mesotérmico, com moderada deficiência de água no inverno (Aw), e a vegetação natural predominante é constituída por Cerrado Tropical Subcaducifólio. A precipitação média anual é de $1.235 \mathrm{~mm}$, com temperatura média máxima anual de $25,3^{\circ} \mathrm{C}$ e mínima anual de $15,5^{\circ} \mathrm{C}$ (SETZER, 1946). Os latossolos constituem-se nas principais unidades de solos da região de Felixlândia (LOPES, 1983).

\subsection{Determinação do teor de umidade, análise granulométrica e densidade do solo}

O teor de umidade foi determinado nos talhões 35, 36, 39, 40, 42 e 44. Com o auxílio do trado mecânico, amostras de solo foram coletadas em quatro repetições/ talhão nas profundidades de $0-10 \mathrm{~cm}$ e $20-40 \mathrm{~cm}$. As amostras foram colocadas em recipientes previamente pesados e lacrados para não perderem a umidade original. As amostras foram pesadas em uma balança de precisão e depois colocadas em uma estufa, no Laboratório de Hidrologia Florestal da Universidade Federal de Viçosa (UFV), na temperatura de $105^{\circ}$ por $20 \mathrm{~h}$ até que o peso das amostras se tornou constante, sendo pesadas novamente na mesma balança de precisão. Esse MétodoPadrão de Estufa é baseado na diferença de peso entre

Revista Árvore, Viçosa-MG, v.36, n.6, p.1091-1097, 2012 
uma amostra contendo água antes e depois de uma secagem. O teor de umidade foi calculado pela seguinte fórmula:

$$
\mathrm{U} \%=\frac{\mathrm{M}_{1}-\mathrm{M}_{2}}{\mathrm{M}_{2}-\mathrm{M}_{3}} \times 100
$$

Sendo:

$\mathrm{M}_{1}=$ peso do solo contendo água + peso do recipiente $(\mathrm{g})$

$\mathrm{M}_{2}=$ peso do solo seco + peso do recipiente $(\mathrm{g})$

$\mathrm{M}_{3}=$ peso do recipiente de amostragem $(\mathrm{g})$

A partir das amostras de solos coletadas a 10 cm de profundidade nos talhões 35, 36, 39, 40, 42 e 44, determinaram-se também a análise granulométrica e a densidade do solo. As análises foram realizadas pelo Laboratório de Rotina do Departamento de Solos da Universidade Federal de Viçosa (UFV), em Viçosa, MG.

\subsection{Determinação da resistência do solo à penetração}

Os testes de resistência do solo à penetração foram realizados nos talhões $35,36,39,40,42$ e 44, com plantios de eucalipto ao longo do mês de fevereiro de 2011 . Foram realizadas no total oito repetições em cada talhão nas linhas de plantio e entrelinhas, em intervalos de $10 \mathrm{~cm}$ de profundidade e atingindo a profundidade de até $50 \mathrm{~cm}$. A altura de lançamento do êmbolo foi de $50 \mathrm{~cm}$.

Os dados de resistência mecânica do solo foram convertidos em MPa, utilizando-se a Planilha do Penetrômetro Versão 1.0 elaborada pela Sondaterra Equipamentos. Na Planilha, colocaram-se a altura de lançamento do êmbolo com massa conhecida de 1,6 kg, os intervalos iniciais e finais de profundidade atingida pelo êmbolo e o número de impactos que foram realizados para atingir os determinados intervalos de $0-10 \mathrm{~cm}, 10-20 \mathrm{~cm}, 20-30 \mathrm{~cm}, 30-40 \mathrm{~cm}$ e $40-50 \mathrm{~cm}$ de profundidade.

\section{RESULTADOS}

\subsection{Teor de umidade, análise granulométrica e densidade do solo}

Durante o período em que foram realizados os testes de resistência mecânica, observou-se que o solo se encontrava com baixo teor de umidade. $\mathrm{O}$ talhão 35 apresentou valores do teor de umidade de $17,28 \%$ e $17,32 \%$, respectivamente nas camadas

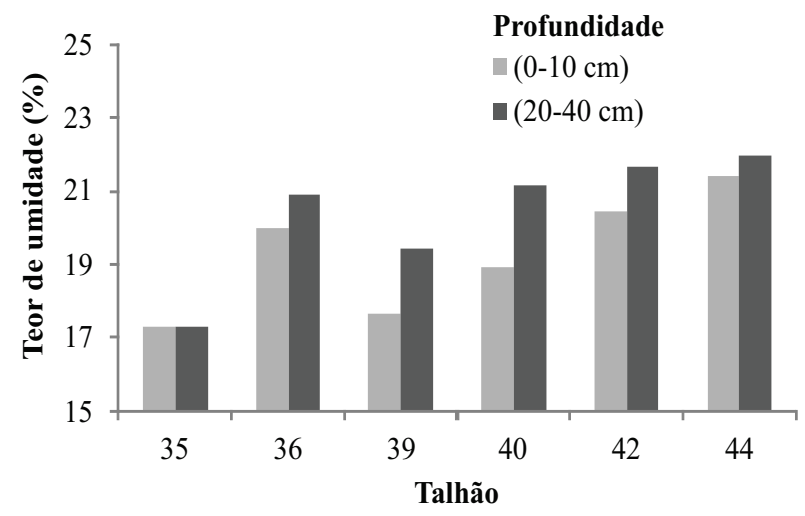

Figura 1 - Teor de umidade nos talhões 35, 36, 39, 40, 42 e 44 nas camadas de $0-10 \mathrm{~cm}$ e $20-40 \mathrm{~cm}$ de profundidades na Bacia Hidrográfica do Riacho Fundo, Felixlândia-MG. Fevereiro, 2011.

Figure 1-Moisture content in plots 35, 36, 39, 40, 42 and 44 at the layers of $0-10 \mathrm{~cm}$ and $20-40 \mathrm{~cm}$ depths in the Riacho Fundo watershade, Felixlândia-MG - February, 2011.

de 0-10 $\mathrm{cm}$ e 0-20 $\mathrm{cm}$ de profundidade, sendo esses valores os mais baixos entre os talhões avaliados (Figura 1).

Em relação à análise granulométrica das amostras de solo, verifica-se, na Tabela 1 , que a classe textural nos talhões 35, 36, 39, 40, 42 e 44 é argilosa.

A densidade do solo nos talhões 35, 36, 39, 40, 42 e 44 foi avaliada na camada de $0-10 \mathrm{~cm}$, e verificou-se que nessa camada a densidade do solo se encontrava com valores compreendidos entre 1,03 e $1,09 \mathrm{~g} \mathrm{~cm}^{-3}$ (Figura 2).

\subsection{Resistência mecânica do solo à penetração}

Os talhões 35, 36, 39, 40, 42 e 44 apresentaram valores de resistência mecânica do solo na profundidade de 0-50 cm, compreendidos entre 4,92 e 6,45 MPa. Como se pode ver na Tabela 2, o talhão 40 apresentou a menor média de resistência mecânica $(4,92 \mathrm{MPa})$ entre os talhões e o talhão 42, a maior $(6,45 \mathrm{MPa})$.

Em relação à camada de $0-10 \mathrm{~cm}$ de profundidade, o talhão 40 também apresentou a menor média de resistência mecânica (3,13 MPa) entre os talhões. E o talhão 39 teve a maior média de resistência mecânica $(5,89 \mathrm{MPa})$ na camada de $0-10 \mathrm{~cm}$ de profundidade entre os talhões (Tabela 2).

Revista Árvore, Viçosa-MG, v.36, n.6, p.1091-1097, 2012 
Tabela 1 - Análise Granulométrica de amostras de solo coletadas na profundidade de $10 \mathrm{~cm}$ nos talhões $35,36,39$, 40, 42 e 44

Table 1 - Particle size analysis of soil samples collected at 10 $\mathrm{cm}$ of depth in plots 35, 36, 39, 40, 42 and 44

\begin{tabular}{cccccc}
\hline \multicolumn{5}{c}{ Análises } & Granulométricas \\
Talhão & $\begin{array}{c}\text { Areia } \\
\text { Grossa }\end{array}$ & $\begin{array}{c}\text { Areia } \\
\text { Fina }\end{array}$ & Silte & Argila & Classe \\
\hline 35 & 4 & 5 & 34 & 57 & Argilosa \\
36 & 3 & 6 & 32 & 59 & Argilosa \\
39 & 8 & 16 & 16 & 60 & Argilosa \\
40 & 6 & 10 & 24 & 60 & Argilosa \\
42 & 4 & 4 & 33 & 59 & Argilosa \\
44 & 3 & 4 & 35 & 58 & Argilosa \\
\hline
\end{tabular}

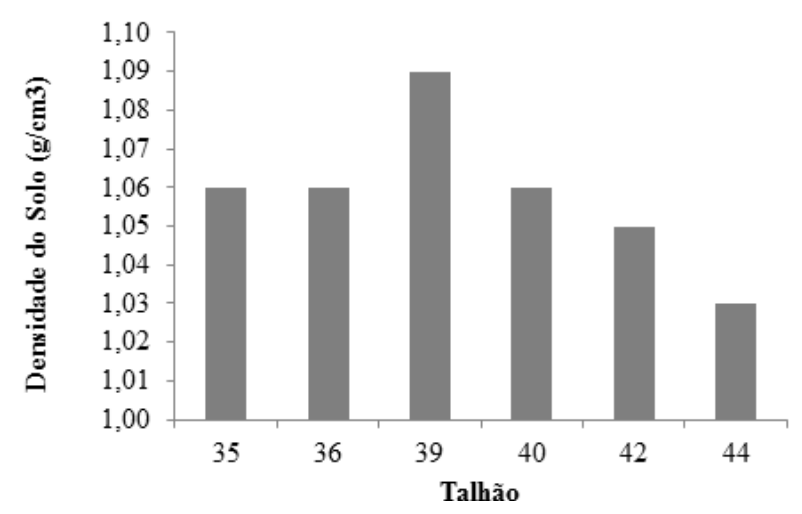

Figura 2 - Densidade do solo na camada de 0-10 cm nos talhões 35, 36, 39, 40, 42 e 44 .

Figure 2 - Particle size analysis of soil samples collected at $10 \mathrm{~cm}$ of depth in plots 35, 36, 39, 40, 42 and 44.

Tabela 2 - Resistência mecânica do solo média nos talhões 35, 36, 39, 40, 42 e 44 na Bacia Hidrográfica do Riacho Fundo, Felixlândia-MG. Fevereiro, 2011.

Table 2 -Average mechanical resistance of soil in plots 35, 36, 39, 40, 42 and 44 in the Riacho Fundo watershade, Felixlândia-MG - February, 2011.

\begin{tabular}{ccc}
\hline Talhão & $\begin{array}{c}\text { Resistência } \\
\text { Mecânica - MPa } \\
0-50 \mathrm{~cm}\end{array}$ & $\begin{array}{c}\text { Resistência } \\
\text { Mecânica - MPa } \\
0-10 \mathrm{~cm}\end{array}$ \\
\hline 35 & 5,47 & 4,07 \\
36 & 5,74 & 3,89 \\
39 & 5,58 & 5,89 \\
40 & 4,92 & 3,13 \\
42 & 6,45 & 5,55 \\
44 & 5,47 & 4,07 \\
\hline
\end{tabular}

Resistência Mecânica (MPa)
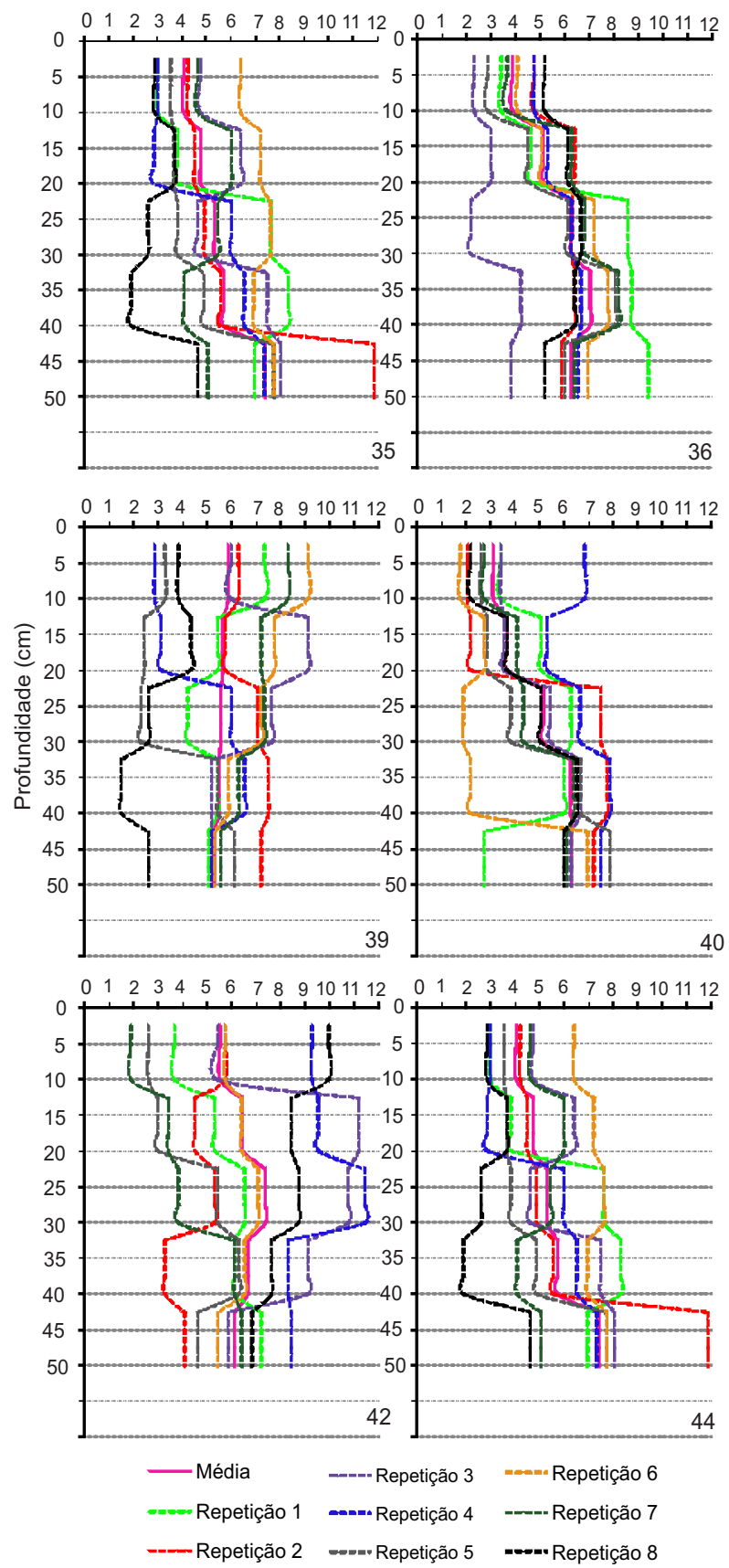

Figura 3 - Resistência mecânica do solo nos talhões $35,36,39,40,42$ e 44 em profundidade variando de $0-50 \mathrm{~cm}$. Felixlândia- MG, fevereiro, 2011.

Figure 3-Mechanical resistance of soil in plots 35, 36, 39, 40, 42 and 44 in depths ranging from 0 to 50 cm. Felixlandia-MG - February, 2011. 
A resistência mecânica foi determinada tanto na linha de plantio quanto nas entrelinhas, e, dessa forma, percebem-se repetições com variações bruscas nos valores de resistência mecânica em cada um dos talhões (Figura 3).

\section{DISCUSSÃO}

\subsection{Análise granulométrica e densidade do solo}

Os talhões 35, 36, 39, 40, 42 e 44 possuem classe textural argilosa e, segundo Tormena et al. (1998), os latossolos de textura argilosa ou muito argilosa apresentam, sob condições naturais, excelentes condições físicas oriundas da microestrutura granular, fortemente desenvolvida, referentes à infiltração de água no solo e à resistência à erosão.

Rigato et al. (2005), estudando a influência dos atributos físicos do solo sobre a produtividade de Pinus taeda aos 12 anos de idade em Telêmaco Borba (PR), verificaram que os sítios de textura argilosa apresentaram maiores valores de porosidade total, enquanto em solos com textura mais arenosa a porosidade total foi menor. Além disso, aqueles autores verificaram também maior produtividade no sítio localizado sobre um Cambissolo de textura argilosa.

A Densidade do solo (Ds) é uma propriedade que avalia a massa de sólidos pelo volume. Os valores normais dos solos arenosos variam de 1,2 a $1,9 \mathrm{~g} \mathrm{~cm}^{-3}$, enquanto solos argilosos apresentam valores mais baixos, de 0,9 a $1,7 \mathrm{~g} \mathrm{~cm}^{-3}$. Os valores de Ds que estão associados ao estado de compactação com alta probabilidade de oferecer riscos de restrição ao crescimento radicular situam-se em torno de $1,65 \mathrm{~g} \mathrm{~cm}^{-3}$ nos solos arenosos e de $1,45 \mathrm{~g} \mathrm{~cm}^{-3}$ em solos argilosos (REINERT; REICHERT, 2006).

De acordo com Camargo e Alleoni (1997), os valores médios considerados ideais para Densidade do solo-Ds estão compreendidos na faixa entre 1,0 e $1,2 \mathrm{~g} \mathrm{~cm}^{-3}$. Dessa forma, como visualizado na Figura 2, a Ds na camada de $0-10 \mathrm{~cm}$ de profundidade nos talhões $35,36,39$, 40, 42 e 44 encontra-se em condições ideais com valores compreendidos entre 1,03 e $1,09 \mathrm{~g} \mathrm{~cm}^{-3}$.

Esses dados podem variar de acordo com a profundidade da camada analisada. No estudo realizado por Cavenage et al. (1999) em seis áreas: cerrado (vegetação natural), culturas anuais (milho-Zea mays L.) em sistema convencional há 18 anos, eucalipto (Eucalyptus camaldulensis), pinus (Pinus caribaea var. hondurensis), mata ciliar (reflorestada com espécies nativas) e pastagem (Brachiaria decumbens), as quais vêm sendo utilizadas, consecutivamente, há 10 anos, e três profundidades $(0,00-0,10 \mathrm{~m}, 0,10-0,20 \mathrm{~m}, 0,20-0,40 \mathrm{~m})$ verificou-se que a densidade do solo diminuiu com o aumento da profundidade, para as áreas, exceto para as áreas com culturas anuais e com cerrado, onde o menor valor encontra-se na primeira camada $(0,00-0,10 \mathrm{~m})$.

Segundo Costa et al. (2003), valores mais elevados de densidade do solo em superfície, em plantios florestais, podem estar relacionados ao tempo de utilização da área, arquitetura do sistema radicular, pouca cobertura do solo durante o período inicial de crescimento das plantas, trânsito de máquinas e implementos agrícolas e condições de umidade do solo no preparo do solo e no plantio das mudas.

\subsection{Resistência mecânica do solo à penetração}

Os talhões 35, 36, 39, 40, 42 e 44 apresentaram valores médios acima de $4 \mathrm{MPa}$ (Figura 3 e Tabela 2). Em relação às camadas de $0-10 \mathrm{~cm}$ e $10-20 \mathrm{~cm}$ de profundidade, o talhão 40 apresentou valores de resistência mecânica média do solo até $4 \mathrm{MPa}$; nas demais camadas analisadas, esses valores se encontravam acima desse (Figura 3 ).

Segundo Arshad et al. (1996), em culturas agrícolas em solos com resistência à penetração maior que 2,0 MPa o crescimento de raízes é limitado, enquanto naqueles com valores abaixo de 1,0 MPa a resistência pode ser assumida como pequena. No entanto, em solos não revolvidos anualmente são toleráveis valores de resistência até $4 \mathrm{MPa}$, devido à permanência e continuidade de poros, atividade biológica mais ativa e maior estabilidade de agregados. Segundo Grant e Lanfond (1993), valores na faixa de 1,5 a 3,0 MPa são restritivos ao crescimento radicular. A penetração de raízes de espécies florestais é geralmente dificultada em resistências do solo a partir da faixa entre 2,5 e 3,0 MPa (GREACEN; SANDS, 1980).

O período no qual foram realizados os testes de resistência mecânica do solo, em fevereiro de 2011, apesar de ser período chuvoso, encontrava-se com o solo em condições de baixo teor de umidade (Figura 1), uma vez que não havia registro de chuva na área experimental há 30 dias. Para Klein et al. (1998), pequenas reduções na umidade proporcionam incrementos acentuados da resistência do solo à penetração.

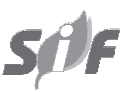

Revista Árvore, Viçosa-MG, v.36, n.6, p.1091-1097, 2012 
No talhão 35 para a camada de $40-50 \mathrm{~cm}$ de profundidade, verificou-se resistência mecânica de 11,86 MPa; no talhão 42 na camada de $20-30 \mathrm{~cm}$, notou-se resistência mecânica de $11,46 \mathrm{MPa}$; e no talhão 44 na camada de $40-50 \mathrm{~cm}$, observou-se resistência mecânica de 11,86 MPa (Figura 3). Assim, constataram-se altos valores de resistência mecânica do solo nos talhões $35,36,39,40,42$ e 44 em condições de baixo teor de umidade do solo.

Em um estudo sobre "Camadas de Impedimento Mecânico do Solo em Sistemas Agrícolas com a Soja" objetivando avaliar a relação entre a densidade global e a resistência do solo à penetração, obtida com penetrômetro, em diferentes teores de umidade em Latossolos Roxos do Norte do Paraná, Torres e Saraiva (1999) verificaram que a resistência à penetração aumentou com a redução dos teores de umidade do solo, e essa tendência foi mais acentuada nas densidades maiores. O mesmo foi também verificado no talhão 39 , que apresentou maior densidade do solo (1,09 $\mathrm{g} / \mathrm{cm}^{3}$ ) em relação aos demais talhões e também maior resistência mecânica do solo $(5,89 \mathrm{MPa})$ na camada de $0-10 \mathrm{~cm}$.

Torres e Saraiva (1999) observaram que no plantio de soja a resistência à penetração foi de 1,5 MPa, quando a umidade do solo estava em torno de $37 \%$; e de 16 $\mathrm{MPa}$, quando a umidade se encontrava em torno de $21 \%$, evidenciando a grande variação da resistência com a mudança dos teores de umidade. Esses autores consideraram ainda que é precipitado definir a compactação do solo utilizando somente as avaliações feitas com o penetrômetro de impacto, sendo, pois, indispensável avaliar outros parâmetros, como o manejo e morfologia do solo para esta conclusão.

\section{CONCLUSÃO}

Os talhões apresentaram valores médios da resistência mecânica do solo acima de $4 \mathrm{MPa}$, e esses altos valores podem estar associados ao uso do solo na Bacia Hidrográfica do Riacho Fundo, que antes dos plantios de eucalipto era pastagem, e também devido à condição de baixo teor de umidade do solo no período em que foi realizada a determinação da resistência mecânica do solo.

É preciso realizar maiores estudos direcionados aos plantios de eucalipto no que diz respeito ao crescimento radicular em solos com resistência mecânica elevada, a fim de verificar a influência do manejo do solo na compactação e desenvolvimento radicular das plantas.

\section{AGRADECIMENTOS}

Ao CNPq, pela concessão da bolsa de estudos; aos estagiários do Laboratório de Hidrologia Florestal (DEF/UFV) Paulo, João Paulo e Lucas, pelo auxílio na execução desta pesquisa; e ao Renato Castro, pelas contribuições.

\section{REFERÊNCIAS}

ARSHAD, M. A.; LOWERY, B.; GROSSMAN, B. Physical tests for monitoring soil quality. In: DORAN, J. W.; JONES, A. J. Methods for assessing soil quality. Madison: Soil Science Society of America, 1996. p.123-141.

BENGOUGH, A. G.; MULLINS, C. E. Mechanical impedance to root growth: a review of experimental techniques and root growth responses. Journal of Soil Science, v.41, n.3, p.341-358, 1990.

CAMARGO, O. A.; ALLEONI, L. R. F. Compactação do solo e o desenvolvimento das plantas. Piracicaba: USP/ESALQ, 1997.132p.

CAVENAGE, A. et al. Alterações nas propriedades físicas de um Latossolo VermelhoEscuro sob diferentes culturas. Revista Brasileira de Ciência do Solo, v.23, n.4, p.997-1003, 1999.

COSTA, F. S. et al. Propriedades físicas de um Latossolo Bruno afetada pelos sistemas plantio direto e preparo convencional. Revista

Brasileira de Ciência do Solo, v.27, n.3, p.527-535, 2003.

GRANT, C. A.; LAFOND, G. P. The effects of tillage systems and crop sequences on soil bulk density and penetration resistence on a clay soil in Southern Saskatchewan. Canadian

Journal of Soil Science, v.73, n.2, p.223232. 1993.

GREACEN, E. L.; SANDS, R. Compaction of Forest soils. A review. Australian Journal of Soil Research, v.18, n.2, p.163-89, 1980. 
KLEIN, V. A.; LIBARDI, P. L.; SILVA, A. P. Resistência mecânica do solo à penetração sob diferentes condições de densidade e teor de água. Engenharia Agrícola, v.18, n.2, p.45-54, 1998.

LOPES, A. S. Solos sob "cerrado": características, propriedades e manejo. Piracicaba: Instituto da Potassa \& Fósforo, 1983. 162 p.

POGGIANI, F. Monitoramento ambiental de plantações florestais e áreas naturais adjacentes. Série Técnica IPEF, v.10, n.29, p.22-35, 1996.

RAPER, R.; ERBACH, D. Prediction of soil stresses using the finite element method. Trans. Am. Soc. Agric. Eng., 33: 725-730, 1990.

REINERT, D. J.; REICHERT, J. M. Propriedades física do solo. Santa Maria: Universidade Federal de Santa Maria/Centro de Ciências Rurais, 2006. 18 p.

RIGATO, M. A.; DEDECEK, R. A.; MATTOS, J. L. M. Influência dos atributos do solo sobre a produtividade de Pinus taeda. Revista Árvore, v.29, n.5, p.701-709, 2005.

SEIXAS, F.; SOUZA, C. R. Avaliação e efeito da compactação do solo, devido à freqüência de tráfego, na produção de madeira de eucalipto. Revista Árvore, v.31, n.6, p.1047-1052, 2007.
SETZER, J. Contribuição para o estudo do clima do Estado de São Paulo. São Paulo: Escolas Profissionais Salesianas, 1946. 239p.

SILVA, S. R et al. Alterações do solo influenciadas pelo tráfego e carga de um "forwarder" nas entrelinhas de uma floresta de eucalipto. Revista Brasileira de Ciência do Solo, v.31, n.2, p.371-377, 2007.

STOLF, R. et al. Measuring mechanical impedance in clayey gravelly soils. Revista Brasileira de Ciência do Solo, v.22, n.2, p.189-196, 1998.

TAVARES FILHO, J. et al. Resistência do solo à penetração e desenvolvimento do sistema radicular do milho (Zea mays) sob diferentes sistemas de manejo em um latossolo roxo. Revista Brasileira de Ciência do Solo v.25, n.3, p.725-730, 2001.

TORMENA, C. A.; SILVA, A. P.; LIBARDI, P. L. Caracterização do intervalo hídrico ótimo de um Latossolo Roxo sob plantio direto. Revista Brasileira de Ciência do Solo, v.22, n.4, p.573-581, 1998.

TORRES, E.; SARAIVA, O. F. Camadas de impedimento do solo em sistemas agrícolas com a soja. Londrina: Embrapa Soja, 1999. 58p. (Embrapa Soja. Circular Técnica, 23). 
